Agata Šega

\title{
«Dejarse caer para después poder quizá levantarse ...» O el tema mitológico del descenso a los infiernos en Rayuela de Julio Cortázar*
}

Palabras clave: Julio Cortázar, Rayuela, Carl Gustav Jung, el descenso a los infiernos, mitología, arquetipos, el proceso de individuación, ánima

DOI: 10.4312 /ars.9.1.166-178

\section{El guante de Cortázar}

En la novela Rayuela, definida por Luis Harss $\left({ }^{8} 1978,269\right)$ como «una obra terapéutica», el autor, Julio Cortázar, pone en la boca de Traveler, el amigo y el segundo yo del protagonista Horacio Oliveira, el consejo siguiente:

Lo malo en vos - dijo Traveler - es que cualquier problema lo retrotraés a la infancia. Ya estoy harto de decirte que leas un poco a Jung, che (41: $391)^{1}$.

En un artículo precedente sobre Rayuela (Šega, 1992) nos permitimos ya por primera vez recoger el guante arrojado por Cortázar con esta frase que nos invita a analizar la novela apoyándonos en la teoría junguiana. En el artículo mencionado tratamos de establecer en qué forma y de qué manera se expresan en Rayuela algunos de los conceptos simbólicos arquetípicos que forman parte del proceso de individuación como lo define Jung ${ }^{2}$. Se mostró que no necesitamos entrar en las profundidades de la teoría del psiquiatra suizo, sino que basta ya la lectura de una obra divulgativa de la teoría junguiana ${ }^{3}$, apoyada por el uso de un diccionario general de símbolos (Chevalier,

* La versión eslovena de este artículo es asequible en: http://revije.ff.uni-lj.si/arshumanitas. / Slovenska različica članka je dosegljiva na http://revije.ff.uni-lj.si/arshumanitas.

1 Citamos siempre el número del capítulo de la novela seguido por el número de página de la edición de Andrés Amorós (Cortázar, 1986).

2 El proceso de individuación es el proceso de auto(re)conocimiento o de autorealización que se efectúa por la integración de los contenidos psíquicos inconscientes en la conciencia. Estos contenidos representan en el fondo las formas arquetípicas universales. Es obligatorio que el individuo los tome en conciencia para alcanzar el grado de sí-mismo, es decir el grado de la unicidad individual que representa la meta del proceso de individuación. Cf. von Franz, M.-L., El proceso de individuación, en: Jung et al., ${ }^{2} 1974,158-229$.

3 Se trata sobre todo del libro El hombre y sus símbolos, escrito por el maestro y algunos de sus alumnos, cf. Jung et al., ${ }^{2} 1974$. 
Gheerbrandt, 1979), para llegar a descubrir las correspondencias con la obra maestra de Julio Cortázar que resultan ser bastante numerosas y sorprendentes.

\section{2 «El gran hasunto»}

En general, los símbolos utilizados en la literatura parecen dividirse en dos grupos. Existen por un lado los símbolos convencionales universalmente conocidos y explicados en los diccionarios de los símbolos y en otras obras especializadas, relacionados con la mitología griega, romana, cristiana y la de otras religiones, y, por el otro, los símbolos individuales, característisticos de cada autor.

Julio Cortázar, un hombre de amplísima cultura, conoce perfectamente la mitología y se sirve de estos símbolos convencionales, pero no es el único a hacerlo; el recurso a la mitología clásica es prácticamente una característica de la literatura del siglo XX. Autores europeos como Nietzsche, Joyce, Unamuno o Camus recurren a la tradición clásica y en la literatura hispanoamericana existe una corriente de clasicismo a la que pertenecen escritores y poetas tan conocidos como Carpentier, Borges y Paz. A lo largo de toda la obra de Cortázar se advierte una repetición de motivos y de figuras clásicas que corresponde perfectamente a esta tendencia general. Este procedimiento de reelaboración de las figuras mitológicas universales, definido por Roberto González Echeverría (1983, 205) como «una búsqueda filológica de una mitología de los orígenes», se explicaría en la teoría junguiana con la aspiración del autor de expresar de manera adecuada su experiencia personal ${ }^{4}$. Sin embargo, en la obra de Cortázar notamos también la presencia de un gran número de símbolos individuales que en realidad no representan nada más (ni nada menos) que estos mismos contenidos mitológicos, simbólicos, arquetípicos más profundos, cargados de una tradición milenaria, pero que aparecen bajo disfraces grotescos o triviales y nos impiden reconocer su naturaleza simbólica (Šega 1992, sobre todo 38-39).

En el artículo sobre los contenidos simbólicos en Rayuela (Šega, 1992) pudimos establecer ya que los contenidos simbólicos se concentran más o menos alrededor de tres temas arquetípicos que tienen una remota y amplia tradición en la cultura occidental y que se relacionan todos con el proceso de individuación como lo define Carl Gustav Jung 5 . Se trata de los temas del sacrificio y de la muerte, del laberinto y de la lucha contra el monstruo y, finalmente, del tema del descenso a los infiernos que nos

4 «It is [...] to be expected that the poet will turn to mythological figures in order to give suitable expression to his experience. [...] the primordial experience is the source of his creativeness, but it is so dark and amorphous that it requires the related mythological imagery to give it form» (Jung, ${ }^{4} 1978$, 96, en el texto "On the relation of the analytical psychology to poetry»).

Ver la nota 2. 
interesará en este lugar. Los capítulos en los que estos tres temas aparecen con mayor intensidad son los capítulos 5, 36, 54 y 56 .

En la tradición mitológica, el simbolismo del sacrificio se relaciona con los antiguos misterios que celebran el poder fertilizador de la Madre Tierra y que encuentran su expresión en los ritos dionisíacos que celebran el ciclo repetido de nacimiento, desarrollo, plenitud y decadencia. Los tres temas arquetípicos mencionados se entrelazan constantemente en Rayuela. En el capítulo 5 aprendemos que el sacrificio hace posible la resurrección: «... allí podía consumarse la resurrección del fenix después que él la hubiera estrangulado deliciosamente ...» (5: 155). La muerte es entonces el descenso a los orígenes que conduce a «un despertarse y conocer su verdadero nombre» (5: 152).

La idea de la resurrección se expande de manera más evidente en los misterios del orfismo donde la muerte lleva una promesa de inmortalidad, porque ofrece la segura y eterna vida en el cielo. Orfeo aparece como un hombre-dios de carácter andrógino que domina los animales y el resto de la naturaleza con su música, es decir, con algo que nace de la intuición, no de la razón. Su paralelo es el dios persa Mithra que con el sacrificio de un toro triunfa sobre las primitivas pasiones animales del hombre (Jung et al., ${ }^{2} 1974,148$ ). Los misterios órficos reemplazan los ritos dionisíacos que, con sus símbolos puramente naturales de vida y amor, se mostraron demasiado salvajes. Pero, según la tradición mitológica, Dioniso también bajó a los infiernos para liberar de allí a su madre. Por esta razón se le considera como a un dios que libera de los infiernos y regala la inmortalidad (Chevalier, Gheerbrandt, 1979, 122).

\section{Las Catábasis en Rayuela}

En la literatura y en la mitología europea y mundial se registra toda una serie de descensos a los infiernos universalmente conocidos empezando por Gilgamesh y pasando no sólo por Dioniso y Orfeo, sino también por Ulíses, Héracles, Eneas, Cristo y Dante, si citamos solamente los más notorios.

En Rayuela encontramos varias alusiones entre líneas al viaje simbólico a los infiernos o al menos a uno de los héroes mitológicos o literarios universalmente conocidos que lo experimentaron, mientras que el acto mismo se ejerce muy evidentemente dos veces, es decir en los capítulos 36 y $54^{6}$.

6 Las sumas numerológicas de estos dos números son iguales o sea $9(=3+6$ o $5+4)$. Pensamos que el simbolismo de los números (y de los sonidos) en Rayuela y quizás en Cortázar en general es un tema que todavía no ha sido considerado con detenimento. 


\subsection{La mirada a través del ojo del culo o el descenso dionisíaco}

Dentro del contexto de la novela, el capítulo 36 representa un punto decisivo, porque comienza en un momento de intensa crisis por la que está pasando el protagonista. Horacio Oliveira se encuentra completamente sólo en París: la Maga, su amante, se ha ido y el grupo de sus amigos, llamado el Club de la Serpiente, se ha disuelto. El capítulo muestra las características típicas de un rito de iniciación. En las sociedades tribales, el rito de iniciación retrotrae al novicio al más profundo nivel de la originaria identidad entre su ego y sí-mismo, forzándolo a experimentar de ese modo una muerte simbólica. El novicio debe abandonar toda ambición intencionada y todo deseo, estar dispuesto a sufrir la prueba sin esperanza de triunfo. Después es rescatado de esa situación mediante el rito del nuevo nacimiento (Jung et al., ${ }^{2} 1974$, 128-136).

La naturaleza ritual del capítulo 36 se manifiesta ya al inicio: como en casi todos los capítulos importantes de la novela, la acción se desarrolla por la noche, que Horacio llama directamente «final del gran juego» (36: 354). La oscuridad de la noche, dominada, normalmente, por los sueños que la razón no ilumina, es el período en que se hace valer el lado oscuro del hombre, el período gobernado por la muerte. Parece que la noche favorece la comunicación y destruye los tabúes. Destacamos además que en esta escena, Cortázar se refiere varias veces a su protagonista con el apodo de $e l$ nuevo: este título parece recalcar las alusiones a la iniciación ritual'7.

La señal representativa de la prueba iniciática en este capítulo es el símbolo del descenso: Oliveira desciende a las orillas del Sena, debajo de un puente, elemento arquitectónico que en las obras de Cortázar a menudo alude a la idea de paso a otras zonas o la posible reconciliación de dos opuestos. Unos detalles de fondo contienen alusiones indirectas y discretas al hecho de que el descenso nocturno de Horacio es una forma de ruptura y de muerte simbólica: Cortázar compara las cajas de los bouquinistes que a Oliveira «le parecían siempre fúnebres de noche», a una «hilera de ataúdes de emergencia» (36: 358). Debajo del puente Oliveira se pone a "pensar un rato en lo del kibbutz», pues «hacía rato que la idea del kibbutz le rondaba, un kibbutz del deseo» (36: 354).

El paralelo del descenso espacial es el descenso social que significa la ruptura definitiva de Horacio con la sociedad burguesa. Margery A. Safir que también subraya

7 El mote «recién llegado» del que habla Margery A. Safir $(1983,227)$ no aparece ni una sola vez en el capítulo 36. 
la naturaleza ritual, hasta iniciática de este capítulo, ${ }^{8}$ observa que, en él, Horacio desciende al mundo de los vagabundos, un grupo social marginal cuya característica más importante es su abstinencia del trabajo que los aproxima a los niños, a los locos -grupos que tienen gran importancia en la literatura de Cortázar porque les atribuye la clarividencia originaria- o, tal vez, hasta a los muertos (Safir, 1983, 229): mientras reflexiona debajo del puente, Horacio escucha los ronquidos de los vagabundos «que venían como del fondo de la tierra» (36: 355). El descenso al mundo de los vagabundos en el que desaparecen los tabúes y la racionalidad, representa para Horacio un paso hacia el otro lado. El descenso de Oliveira se opera también sobre el plano moral. El vino que toma es un factor muy importante en este proceso: «Y aunque Holiveira desconfiara de la hebriedad, hastuta cómplice del Gran Hengaño, algo le decía que también allí había kibbutz ...» (36: 361).

Ya en los ritos dionisíacos, al vino se le suponía productor del simbólico rebajamiento de la consciencia, necesario para que el novicio se introduzca en los secretos de la naturaleza y experimente el poder de la Madre Tierra (Jung et al., ${ }^{2} 1974$, 141). Esto es exactamente lo que sucede en las visiones alucinatorias que tiene Horacio cuando está borracho. En estas visiones en las que la violencia y el erotismo reinan incontrolados, el objeto del comportamiento erótico y de la violencia es una diosa que se define como la Gran Madre. En lugar de la veneración religiosa la diosa que Horacio confunde con la vagabunda Emmanuèle sufre un destino completamente opuesto:

... su cara se enciende a cada chupada de cigarillo y Oliveira veía las placas de mugre en la frente, los gruesos labios manchados de vino, la vincha triunfal de alguna diosa siria [...] con placas de sangre y mugre pero conservando la diadema eterna a franjas rojas y verdes, la Gran Madre tirada en el polvo y pisoteada por soldados borrachos que se divertían en mear contra los senos mutilados [...] masturbándose contra el mármol ... (36: 361).

Inconscientemente, Horacio se da cuenta del mensaje de esta visión. Se decide conscientemente realizar la última lección de Heráclito que «se había hecho enterrar en un montón de estiércol para curarse la hidropesia ...» (36: 362) porque vé que no le ha servido para nada «entablar contacto por el buen lado, reinventar el amor como la sola manera de entrar alguna vez en su kibbutz ...» (36: 362).

Entonces tal vez fuera eso, estar en la mierda hasta el cogote y también esperar, porque seguramente Heráclito había tenido que quedarse en la mierda días enteros, y Oliveira se estaba acordando de que también Heráclito había dicho que si no se esperaba jamás se encontraría lo inesperado ... (36: 362).

8 «Dentro del contexto de la novela, el capítulo 36 constituye una especie de ritual de iniciación ...» que «... pone fin a la aventura parisiense del protagonista y le impulsa a cruzar el Atlántico y regresar a Buenos Aires» (Safir, 1983, 227). 
Así, Horacio se entrega a un acto erótico transgresivo en público con la vagabunda. Por el trato con la fetidez y la fecalidad, representada por Emmanuele, quiere contravenir la falsa decencia, transponer el límite de tolerancia normal, «dejarse caer para después poder quizá levantarse» (36: 366), «tirarse al suelo como Emmanuele y desde ahí empezar a mirar desde la montaña de bosta ...» (36: 369).

Es evidente que para ascender a alturas insospechadas, Horacio rompe las barreras morales y sociales. Su viaje a las profundidades refleja una entera tradición religiosa y mitológica occidental de descensos redentores (Chevalier, Gheerbrant, 1979, 520), simbolizando el descenso al inconsciente para conocerlo e incluirlo en la consciencia. En este proceso la destrucción y la transgresión se ven como fuerzas redentoras: «... la gente agarraba el calidoscopio por el mal lado, entonces había que darle vuelta..., mirar el mundo a través del ojo del culo ...» (36: 369).

Al final del capítulo aparece la solución del problema:

... por los mocos y el semen y el olor de Emmanuele y la bosta del Oscuro se entraría al camino que llevaba al kibbutz allá lejos pero en el mismo plano, como el Cielo estaba en el mismo plano que la Tierra en la acera roñosa de los juegos ... (36: 369).

Ya al comienzo del capítulo, Horacio había previsto que se encontraría una solución o al menos un alivio provisional: «Probablemente iba a llover, el sauce estaba como suspendido en el aire húmedo» (36: 360). Los dioses griegos se acercaban con frecuencia a sus amadas mortales en forma de lluvia sagrada. En los misterios eleusinos, se consideraba que la lluvia era una «unión amorosa» entre el cielo y la tierra9. De este modo, puede decirse que la lluvia representa una «solución» en el sentido literal de la palabra. El capítulo 21 de la novela ofrece una confirmación de esta suposición: «Y con tanta ciencia una inútil ansia de tener lástima de algo, de que llueva aquí dentro, de que por fin empiece a llover, a oler a tierra, a cosas vivas, sí, por fin a cosas vivas» (21: 235).

El capítulo 36 termina entonces en una forma de liberación, aunque al protagonista lo detenga la policía: «Todo estaba tan bien, todo llegaba a su hora ...» (36: 369). Pero parece que no se trata de una liberación definitiva: el descenso se repite otra vez en Rayuela y, como ya sugiere Margery Safir (1983, 251), también en una de las obras posteriores de Cortázar, el Libro de Manuel.

9 La diosa Demeter, la figura central de los misterios eleusinos, es también uno de los personajes míticos que descienden a los infiernos. Kerényi describe así la esencia del baño ritual: «Demeter Erinys bathed in the river Ladon after her anger had passed, and became Demeter Lusia; her new title signified renewal through purification by watern (Jung, Kerényi 1985, 178; cursiva de A. Š.). Su orígen etimológico es el verbo griego $\lambda u ́ \omega$, cuya raíz se considera paralela a la del verbo latín solvere (de ${ }^{*} s e-$ luo). Cf. Chantraine, 1968, s.v. 


\subsection{El agujero de Eleusis o el descenso órfico}

En el capítulo 54, definido por José Lezama Lima como «páginas decisivamente excepcionales» que "señalan una nueva marca en la novelística americana» y en las cuales los símbolos "están encontrados con una terible precisión ...» (Lezama Lima, 1981, 204), asistimos a otro descenso. Horacio, su amigo Traveler y la mujer de este último, Talita, trabajan al final de la novela en un manicomio de Buenos Aires. Una noche, cuando está de servicio, Horacio sufre una crisis nerviosa en la que empieza a tener miedo de que alguien lo mate:

La idea de que alguien tratara de matarlo no se le había ocurrido hasta este momento a Oliveira, pero le bastó un dibujo instantáneo, un esbozo que tenía más de escalofrío que otra cosa, para darse cuenta de que no era una idea nueva ... (54: 475).

Como ya tantas veces antes, tiene miedo de un agujero imaginado: «... ahora estaba al borde del pozo, agujero de Eleusis, la clínica envuelta en vapores de calor acentuaba el pasaje negativo, los vapores de la solfatara, el descenso» (54: 476). En este momento de angustia intensa, Talita le visita para traerle un refresco. Advierten que uno de los locos, cuya locura consiste en acariciar constantemente una paloma, acaba de ascender del sótano de la clínica en cuyo refrigerio se guardan los muertos que simboliza las profundidades del infierno de Dante. Cortázar mismo alude a esta conexión: «Estaba en su pequeño cómodo Hades refrigerado ... [...], pero no había ninguna Eurídice» (54: 497). Según Jung, la paloma simboliza los profundos y útiles impulsos inconscientes que señalan un camino (Jung et al., ${ }^{2} 1974,176$ ). Además, en la Grecia Antigua, la paloma se considera como el símbolo de la Gran Madre (Chevalier, Gheerbrant, 1979, 169). El arquetipo de la Gran Madre aparece ya en el capítulo 36, en la ocasión del primer descenso de Oliveira, en la imagen de la diosa profanada y podría parecer extraño que esta vez, al contrario, aparezca en su forma más sublimada. Este hecho también se puede explicar con la teoría junguiana: ésta nos enseña que, mientras que «algunos hombres necesitan ser despertados y experimentar su iniciación en la violencia de un dionisíaco rito tonante», lo que se podría comparar con el primer descenso de Oliveira que incluye el dionisíaco rebajamiento de la consciencia con la ayuda del vino, «otros necesitan ser sometidos y son llevados a la sumisión en el designio ordenado del recinto del templo o de la cueva sagrada» (Jung et al., ${ }^{2} 1974$, 149). Hemos visto que Cortázar menciona explicitamente el "pozo», el «agujero de Eleusis», los "vapores de la solfatara» (54: 476) a los cuales Oliveira tiene un miedo inexplicable, semejante al temor que se siente ante la presencia de un dios. Este miedo disminuye notablemente con la llegada de Talita que Oliveira acaba de tomar por la Maga. 


\section{Las Beatrices cortazarianas}

Según la teoría de Jung, el viaje solitario o peregrinación espiritual en la que el iniciado entra en conocimiento con la naturaleza de la muerte es un símbolo trascendente. Pero la muerte no aparece como un juicio final u otra prueba iniciatoria. Es un viaje de liberación, presidido y mantenido por cierto espíritu de compasión representado por una «maestra», es decir, una figura femenina suprema que Jung denomina ánima (Jung et al., ${ }^{2} 1974,31$ y 177-188). El ánima, la personificación de todas las tendencias psicológicas femeninas en la psique de un hombre, adopta el papel de guía, o mediadora, en el mundo inferior y abre el camino hacia profundidades interiores más hondas, hacia sí-mismo ${ }^{10}$. Marie-Louise von Franz (Jung et al., ${ }^{2} 1974,183$ ) menciona algunos ejemplos especialmente claros de cómo el ánima se experimenta: la iniciación de chamanes a los que su lado interno femenino les capacita para ponerse en relación con la «tierra de los fantasmas», el «Paraíso» de Dante en el que el papel de Beatrice es de iniciarle en una forma de vida más espiritual, y otros casos semejantes.

Todos estos elementos se notan en el capítulo 54 de Rayuela. Hemos señalado ya los paralelos del descenso de Oliveira en la literatura y mitología, la presencia de la idea de la muerte. Dice Oliveira a Talita que, en el momento de su aparición, «estaba en pleno trance shamánico» (54: 427). Aparece también la idea de compasión: «El pasado se invertía, cambiaba de signo, al final iba a resultar que La Piedad no estaba liquidando. Esa mujer jugadora de rayuela le tenía lástima, era tan claro que quemaba» (54: 480). La mujer cortazariana es entonces la encarnación del ánima, la intercesora del otro mundo en la tierra. Las personificaciones más típicas y evidentes de este principio femenino en Rayuela son sin duda la Maga y Talita, pero no hay que olvidar que se puede llegar al Cielo también descendiendo a los infiernos, es decir también por el contacto con la vagabunda Emmanuèle o con otros personajes semejantes, por ejemplo con la pianista fracasada Berthe Trépat en el capítulo 23.

Mencionemos en este contexto un artículo reciente de Capitán Gómez (2008), en el que el autor intenta un análisis mitocrítico del cuento Un manuscrito hallado en un bolsillo y descubre en él temas y motivos órficos, incluso naturalmente el tema del descenso al Averno. Señala además varios paralelismos temáticos entre la novela y el cuento que analiza (Capitán Gómez 2008, 182-183). Destaquemos aquí también el hecho que el protagonista del cuento se llama $\mathrm{O}$ - una vocal que no sólo simboliza un agujero, un pasaje hacia el otro lado, sino que establece la conexión tanto con Orfeo como con Oliveira.

10 El sí-mismo es una especie de «átomo nuclear» de la psique, su centro organizador del cual emanan las imágenes oníricas. Según von Franz (Jung et al., ${ }^{2} 1974,161$ ), Jung lo describe como «la totalidad de la psique para distinguirlo del ego que es sólo una pequeña parte de la totalidad de la psique». 


\section{5 ¡Que leas un poco a Jung, che!}

En Rayuela se trata entonces, como dice el mismo Cortázar en una entrevista, de una búsqueda, al final de la que «el hombre se encontraría consigo mismo en una suerte de reconciliación total y de anulación de diferencias» (Harss, $\left.{ }^{8} 1978,267\right){ }^{11}$. En este escritor argentino la realidad más cotidiana, trivial y hasta grotesca se ofrece entonces como punto de partida para la búsqueda del sentido más profundo de la vida y desfigura las imágenes arquetípicas eternas de la mitología clásica. El descenso a los infiernos es en realidad la salida hacia el cielo, el contacto con lo otro es el viaje hacia sí mismo (o sí-mismo), hacia su propio centro interior.

Podríamos, finalmente, preguntarnos si la aparición de estos motivos arquetípicos en Cortázar que transforma algunos pasajes en ilustraciones típicas de la teoría de Jung (¡sin que sea diminuido por eso su valor literario!) es consciente o inconsciente. La respuesta final se substrae a la razón, pero se podría decir que no es ni completamente consciente ni completamente inconsciente. No obstante, hay que tomar en cuenta el hecho de que en la biblioteca personal de Julio Cortázar ${ }^{12}$, al lado de varios tratados sobre la mitología clásica y al lado del diccionario de los símbolos de Jean Chevalier y Alain Gheerbrandt que citamos también en este artículo, se encuentran asimismo varios libros de Carl Gustav Jung. Ana Hernández del Castillo $(1981,7)$ sostiene que Cortázar conocía bastante bien las teorías de Jung sobre la relación de los símbolos que encontramos en los sueños y en los mitos con la estructura de la psique y continúa así:

From my own conversations with the author, I know he was acquainted not only with the works of Jung himself but also with Joseph Campbell's The Hero with a Thousand Faces (first published in 1948) - a work which he highly recommended - and Erich Neumann's Art and the Creative Unconscious (first published in 1959) [... $]^{13}$. I do not exactly know when he read these books, and I have found no mention of them in his essays. These studies apparently provided additional information in themes he had first chosen instinctively.

11 Esta definición de Cortázar corresponde perfectamente a la definición del proceso de individuación en la teoría junguiana que citamos en la nota 2 de este artículo.

12 Accesible en http://www.march.es/bibliotecas/repositorio-cortazar/?l=1.

13 Citemos un pasaje interesante del libro de Erich Neumann que podría definir tanto la búsqueda de Oliveira como el concepto junguiano del proceso de individuación: «The story of the hero, as set forth in the myths, is the history of this self-emancipation of the ego, struggling to free itself from the power of the unconscious and to hold its own against overwhelming odds" (Neumann, E., The Origins and History of Consciousness, New York 1954, pág. 127; citado por Reedy, 1970-71, 226). Ver también la nota 11 . 
La última frase nos parece muy significativa desde el punto de vista de lo que dice Cortázar en una entrevista ${ }^{14}$ sobre la aparición o, mejor dicho, sobre la irrupción repentina en su imaginación de escritor de otro tema no menos arquetípico que el que tratamos aquí. Concluímos entonces nuestras reflexiónes sobre el tema del descenso a los infiernos en Rayuela con la transcripción de las palabras de Cortázar mismo sobre el tema de laberinto y de Minotauro, elaborado en su obra Los Reyes, escrita en el año 1949, es decir 14 años antes de Rayuela:

... un día, de golpe, así, en un viaje de los en que te aburres, de golpe sentí toda la presencia de algo que resultó ser pura mitología griega; lo cual creo que le da razón a Jung y a su teoría de los arquetipos, ¿no?, en el sentido de que todo está en nosotros, que hay una especie de memoria de los antepasados y que por ahí un ... un archibisabuelo tuyo que vivió en Creta 4000 años antes de Cristo, pues a través de los génesis de los cromosomas te manda así algo que corresponde a su tiempo y no al tuyo. Y tú, sin darte cuenta, escribes un cuento o una novela y en realidad estás transmitiendo un mensaje muy muy antiguo y muy arcáico. No tengo otra explicación que dar a parte de aquella que es muy bonita, tú admitirás ...

\section{Bibliografía}

\section{Texto}

Cortázar, J., Rayuela (ed. Amoros, A.), Madrid 1986.

Cortázar, J., Ristanc (trad. Velkovrh Bukilica, V.), Ljubljana 1995.

\section{Obras sobre Cortázar}

Capitán Gómez, F. J., Orfeo y Euridice en un relato de Julio Cortázar, Amaltea. Revista de mitocrítica, 2008, pp. 171-198, http://revistas.ucm.es/index.php/AMAL/article/ view/AMAL0808110171A/20631 [17. 11. 2014].

Harss, L., Los nuestros, Buenos Aires ${ }^{8} 1978$.

González Echevarría, Los Reyes: Mitología de la obra literaria de Cortázar, en: Julio Cortázar: La isla final (eds. Alazraki, J., Ivask, I., Marco, J.), Madrid 1983, pp.199221.

Lezama Lima, J., Cortázar y el comienzo de la otra novela, en: Julio Cortázar (ed. Lastra, P.), Madrid 1981, pp. 191-206 (reimp. de: Casa de las Américas, año 7, 49, julio-agosto 1968, pp. 51-62).

14 Entrevista para la emisión A fondo de la Televisión Española, hecha por Joaquín Soler Serrano en 1977 y accesible actualmente en la página https://www.youtube.com/watch?v=_FDRIPMKHQg. 
Picon Garfield, E., ¿Es Julio Cortázar un surrealista?, Madrid 1975.

Reedy, D. E., The Symbolic Reality of Cortázar's Las Babas del diablo, Revista Hispánica Moderna 36 (4), 1970-1071, pp. 224-237, http://sites.davidson.edu/spa270bfall13/ wp-content/uploads/2013/08/Reedy-Symbolic-Reality-of-Cortazars-Las-babasdel-diablo.pdf [24. 11. 2014].

Safir, M. A., Para un erotismo de la liberación: Notas sobre el comportamiento transgresivo en Rayuela y Libro de Manuel, en: Julio Cortázar: La isla final (eds. Alazraki, J., Ivask, I., Marco, J.), Madrid 1983, pp. 223-251.

Šega, A., Otro modo de jugar a la Rayuela, Verba hispanica 2, 1992, pp. 31-40.

\section{Otras obras}

Chantraine, P., Dictionnaire étymologique de la langue grecque: histoire des mots, París 1968, https://archive.org/details/Dictionnaire-Etymologique-Grec [24. 11. 2014].

Chevalier, J., Gheerbrant, A., Rječnik simbola, Zagreb 1987.

Jung, C. G. et al., El hombre y sus símbolos, Madrid ${ }^{2} 1974$; trad. eslov. Človek in njegovi simboli, Ljubljana 2002.

Jung, C. G., The spirit in man, art and literature (The collected works of C. G. Jung, vol. 15), Princeton ${ }^{4} 1978$.

Jung, C. G., Kerényi, C., The science of Mythology, Londres, Nueva York 1985. 


\section{Agata Šega}

\section{Mitološki motiv spusta $v$ podzemlje v romanu Ristanc Julia Cortázarja}

Ključne besede: mitologija, Julio Cortázar, Ristanc, Carl Gustav Jung

Uporaba antične mitologije je značilna za literaturo 20. stoletja, $v$ hispanoameriški književnosti v zvezi s tem izpostavljajo predvsem Jorgeja Luisa Borgesa in Octavia Paza, omeniti pa velja tudi Julia Cortázarja. Namen prispevka je s tega zornega kota analizirati nekatere prizore iz njegovega romana Ristanc. Poskusili bomo odkriti skriti smisel na videz vsakdanjih dogodkov $\mathrm{v}$ romanu, ki poleg neposrednega in površinskega vsebujejo še globlji simbolični in arhetipski pomen. Zanimali nas bodo predvsem motivi, dejanja in osebe romana, ki evocirajo mitološko tematiko spusta $\mathrm{v}$ podzemlje. Ta motiv, ki je tesno povezan z motivom vstajenja od mrtvih, se ponavlja $\mathrm{v}$ številnih antičnih mitih in se večkrat pojavlja tako v starejši kot tudi sodobni književnosti. Opirali se bomo na teorijo Carla Gustava Junga, po kateri mitološke vsebine človeškemu duhu predstavljajo vrojene in vanj dedno vsajene oblike, ter poskusili izpostaviti tiste simbolične predstave pri Cortázarju, ki so povezane s to mitološko snovjo in prikazane $\mathrm{v}$ zbanalizirani in trivializirani obliki v različnih poglavjih romana Ristanc, predvsem v 36. in 54. poglavju. To ni slučaj, saj glavni junak, cortazarski iskalec, prav na teh dveh mestih $v$ romanu vstopi $v$ iniciacijsko fazo razvoja svoje osebnosti in $s$ tem začne veliko potovanje na drugo stran, ki je $\mathrm{v}$ resnici jungovsko potovanje $\mathrm{k}$ samemu sebi, $\mathrm{k}$ svojemu lastnemu bistvu. 
Agata Šega

\title{
The Mytholotical Motif of Entering the Underworld in Julio Cortázar's Novel Rayuela (Hopscotch)
}

\author{
Keywords: mythology, Julio Cortázar, Hopscotch, Carl Gustav Jung
}

Twentieth-century literature frequently made use of classical mythology, and in Hispano-American literature especially Jorge Luis Borges and Octavio Paz come to mind in the regard, while Julio Cortázar also deserves mention. This paper aims to analyse from this perspective a few scenes from his novel Rayuela (Hopscotch). It will attempt to uncover the hidden meaning of seemingly quotidian events in the novel which, in addition to the direct and the superficial, contain an even deeper symbolic and archetypical meaning. Of primary interest are the motifs, actions, and characters in the novel which evoke the mythological theme of entering the underworld. This motif, which is closely linked with the motif of rising from the dead, is repeated in many classical myths and often appears in both older and contemporary literature. Relying on Carl Gustav Jung's theory, according to which mythological content represents innate and inherited forms of the human mind, the paper highlights those symbolic representations in Cortázar that are linked to mythological material and which are shown in a banal and trivial form in various chapters of the novel Hopscotch, especially in chapters 36 and 54. This is no coincidence, as it is precisely in these two places that the main protagonist, Cortázar's seeker, enters an initiation phase for development of his personality and with that commences the long journey to the other side which is in fact a Jungian journey to himself, to his own essence. 